\title{
Métodos para avaliação retrospectiva da qualidade de um estudo de impacto ambiental
}

A revisão da qualidade dos estudos de impacto ambiental tem sido apontada como um aspecto importante da avaliação do desempenho do processo de avaliação de impacto ambiental. O presente trabalho objetiva avaliar a qualidade de um estudo de impacto ambiental. Para tanto, três ferramentas distintas para revisão da qualidade foram aplicadas. Os resultados encontrados indicam que os métodos permitiram conclusões a respeito da qualidade do estudo avaliado, contribuindo para a identificação de deficiências. Ao final, concluiu-se que os métodos empregados, mesmo com limitações, são importantes, apresentando viabilidade para análise da qualidade dos estudos de impacto ambiental.

Palavras-chave: Meio Ambiente; Impacto Ambiental; Revisão da Qualidade.

\section{Methods for Retrospective Quality Assessment of an Environmental Impact Study}

Reviewing the quality of environmental impact studies has been cited as an important aspect of performance evaluation of the environmental impact assessment process. This paper aims to evaluate the quality of an environmental impact study. To this end, three distinct quality review tools were applied. The results indicate that the methods allowed conclusions about the quality of the evaluated study, contributing to the identification of deficiencies. In the end, it was concluded that the methods employed, even with limitations, are important, presenting feasibility for quality analysis of environmental impact studies.

Keywords: Environment; Environmental impact; Quality Review.

Topic: Planejamento, Gestão e Políticas Públicas Ambientais

Reviewed anonymously in the process of blind peer.
Received: $15 / 10 / 2018$

Approved: 17/11/2018
Hugo Tzauyang Bertuola

Universidade Federal de São Paulo, Brasil

http://lattes.cnpq.br/5487105091887032

http://orcid.org/0000-0002-3661-0738

hugobertuola@hotmail.com

Giovano Candiani (it)

Universidade Federal de São Paulo, Brasil http://lattes.cnpq.br/995099576522975 http://orcid.org/0000-0001-9896-4390

giovanocandiani@gmail.com
Referencing this:

BERTUOLA, H. T.; CANDIANI, G.. Métodos para avaliação retrospectiva da qualidade de um estudo de impacto ambiental. Revista lbero Americana de Ciências Ambientais, v.9, n.8, p.282-298, 2018. DOI: http://doi.org/10.6008/CBPC2179-6858.2018.008.0025 


\section{INTRODUÇÃO}

A ação do homem sobre o meio ambiente é inerente à sua própria história. Entretanto, nas últimas décadas, os efeitos ambientais danosos intensificaram-se de forma insustentável. "O crescimento demográfico concentrado especialmente nos grandes centros urbanos intensifica a exploração dos recursos naturais, limitados face ao modelo de desenvolvimento que requer demanda ilimitada de alimentos, água, bens de consumo e energia" (PEREIRA et al., 2014).

A avaliação de impacto ambiental, caracteriza-se como um processo e instrumento analítico, visando antever as possíveis consequências de um projeto ou empreendimento. Portanto, atribui-se um caráter prévio e preventivo. Sánchez (2013) relata que os primeiros estudos ambientais no Brasil foram realizados para alguns grandes projetos hidrelétricos na década de 1970, em grande parte, como reflexo da influência de demandas exteriores devido à atuação de agentes financeiros de organizações internacionais. As principais etapas do processo de avaliação de impacto ambiental são: apresentação da proposta, triagem, determinação do escopo (scoping), elaboração do estudo de impacto ambiental, análise técnica do estudo de impacto ambiental, consulta pública e decisão (SÁNCHEZ, 2013).

Um estudo de impacto ambiental deve contemplar, no mínimo, as seguintes atividades técnicas: diagnóstico ambiental, análise dos impactos ambientais, definição das medidas mitigadoras e elaboração de programas ambientais (BARBIERI, 2011; ROSA et al., 2012; SÁNCHEZ, 2013; PEREIRA et al., 2014). Além destes itens, o estudo deve apresentar o Relatório de Impacto Ambiental (RIMA).

Uma das funções do estudo de impacto ambiental é analisar a viabilidade ambiental de uma determinada proposta, antecipando as consequências futuras de uma decisão tomada no presente (SÁNCHEZ, 2013; ALMEIDA et al., 2015). Sánchez (2013) relata muitos problemas quanto à qualidade dos estudos ambientais, apontando muitas deficiências, considerando-os muitas vezes em critérios, como: 'muito ruins' ou 'ruins', sobretudo pela identificação e análise precária dos impactos ambientais.

Sánchez (2013) menciona que, no Brasil, vários estudos retrospectivos apontam para a existência de muitos problemas de qualidade, como: definição inadequada em relação ao escopo dos estudos, ausência de termos de referência, medidas mitigadoras genéricas, planos de monitoramento superficiais, desconsideração de impactos sociais, omissões e previsões subestimadas de impactos, falta de menção a estudos de alternativas locacionais e tecnológicas, imprecisão na definição da área afetada e de influência, estudos tendenciosos, etc.

O Ministério Público Federal (MPF, 2004), estudando uma amostra de oitenta EIAs, identificou várias deficiências, como: ausência de proposição alternativa, desconsideração da bacia hidrográfica, prazos insuficientes para a realização de pesquisa de campo, ausência ou insuficiência de informações metodológicas, ausência de mapas temáticos, apresentação de informações inexatas, imprecisas ou contraditórias, deficiências na amostragem para o diagnóstico e ausência de dados quantitativos sobre a vegetação. 
Além desses, ausência de dados sobre organismos de determinados grupos ou categorias, ausência de estudos referente ao patrimônio cultural, não identificação de determinados impactos negativos, omissão de dados, proposição de medidas de mitigação e compensação de impactos que não são a solução adequada, erros conceituais na indicação de programas de monitoramento e acompanhamento ambiental, RIMA incompleto e com linguagem inadequada à compreensão do público, etc. (SÁNCHEZ, 2013).

Vários trabalhos têm focado na avaliação da qualidade dos estudos de impacto ambiental como um indicador de desempenho do processo de avaliação de impacto ambiental, mas a má qualidade de boa parte destes estudos é apontada como um dos principais problemas da aplicação deste instrumento (RAIMUNDO et al., 2012; MONTAÑO et al., 2014).

Conforme menciona Sánchez (2013), existem muitas ferramentas para análise e avaliação dos estudos ambientais. Uma técnica de análise é a avaliação com base no conteúdo dos itens que compõe um estudo ambiental, este procedimento é conhecido como Lee and Colley Review Package (LEE et al., 1999). De acordo com Raimundo et al. (2012) além do procedimento de Lee and Colley, é possível descrever outras técnicas de avaliação da qualidade dos estudos ambientais.

Na Inglaterra, Hickie et al. (1998) elaborou uma lista de verificação com 14 seções e 174 critérios de análise, no Brasil, Pinho et al. (2007), utilizaram uma ferramenta de análise com 12 critérios para revisão da qualidade de estudos de impacto ambiental em pequenas centrais hidrelétricas. Barker et al. (1999), utilizando listas de verificações analisaram 24 estudos ambientais em 8 países europeus. Gray et al. (2003) utilizou a ferramenta desenvolvida por Glasson et al. (2005) para revisão da qualidade de 89 estudos relativos ao setor florestal britânico (RAIMUNDO et al., 2012; SÁNCHEZ, 2013; MONTAÑO et al., 2014; MOUNIR, 2015; FONSECA et al., 2016; VERONEZ et al., 2017). Neste contexto, o objetivo desse trabalho foi avaliar a qualidade de um estudo de impacto ambiental.

\section{METODOLOGIA}

Adotou-se como objeto de estudo o sistema paulista de avaliação de impacto ambiental, que tem como órgão licenciador a Companhia Ambiental do Estado de São Paulo (CETESB). A análise de qualidade de um estudo de impacto ambiental foi realizada pela seleção entre os estudos submetidos ao licenciamento ambiental no estado entre janeiro de 2015 e dezembro de 2017. A escolha do estudo de impacto ambiental avaliado se deu por meio do enquadramento deste aos seguintes critérios: complexidade, caracterizando-se pela instalação de vários sistemas operacionais e estruturas de apoio e localização, área de instalação em região de relevância importância em termos de conservação ambiental.

A proposta foi avaliar a qualidade deste estudo de impacto ambiental, por meio de uma análise de revisão retrospectiva, adotando-se critérios propostas na literatura. Os critérios definidos e usados neste trabalho apresentam ampla aplicação e são procedimentos consagrados na literatura, aspectos que viabilizaram seu uso para análise da qualidade do estudo.

Neste contexto, para o desenvolvimento do presente trabalho foram aplicadas as seguintes ferramentas avaliativas: Lista de verificação (tabela 1) para análise técnica de estudos de impacto ambiental, 
baseada nos trabalhos de Sánchez (2013). O uso desta listagem deu-se pela importância dela, pois constitui uma das poucas listas de verificação disponíveis em português, apresentando 46 critérios e ampla aplicação. Este guia de análise apresenta critérios, subitens e seções típicas de uma estrutura de estudo de impacto ambiental.

Destacam-se os seguintes aspectos: sumário, introdução, informações gerais, caracterização do empreendimento, diagnóstico ambiental, análise dos impactos, programas de gestão ambiental, síntese e conclusões, descrição da equipe técnica, anexos e relatório de impacto ambiental. Neste caso, a análise para a avaliação dos critérios se deu pelo seu atendimento ('sim') ou não ('não') de cada um dos itens (critérios) avaliados (RAIMUNDO et al., 2012).

Outra ferramenta avaliativa foi o Procedimento (tabela 2) Lee and Colley Review Package (LEE et al., 1999). Esta técnica foi desenvolvida por Lee et al. (1992), a avaliação se dá atribuindo conceitos ou notas (A, B, C, D, E, F ou N/A, critério não aplicável) (tabela 3) para cada área, categoria, subcategoria e ainda uma nota geral ao estudo de impacto ambiental. $O$ procedimento analítico é organizado em 4 áreas principais (descrição do projeto e do ambiente afetado, identificação e avaliação de impactos-chave, consideração de alternativas e medidas mitigadoras e comunicação dos resultados).

Para cada uma destas áreas, são estabelecidas 17 categorias, subdivididas em 52 subcategorias, que se caracterizam como os critérios orientadores da análise da qualidade do estudo de impacto ambiental. Estes critérios são organizados, a partir de uma estrutura hierárquica piramidal, formando no total, 73 critérios, conforme ilustra a figura 1.0 procedimento de avaliação inicia-se pela análise dos critérios inseridos no nível inferior da pirâmide (base), estendendo-se em direção ao topo. A cada nível avaliado, a análise tornase mais complexa, atingindo a avaliação global do estudo de impacto ambiental.

Este procedimento adota critérios baseados em boas práticas internacionais e segundo o procedimento estabelecido, o estudo analisado deve ser avaliado separadamente por duas pessoas e as eventuais diferenças devem ser discutidas posteriormente. No presente trabalho, tal tarefa foi realizada conjuntamente (VERONEZ et al., 2017).

Outra ferramenta é o Procedimento, estando esse proposto na tabela 4, e apresentado por Pinho et al. (2007). É formado por critérios que abordam 12 seções associadas a análise do estudo ambiental. Destacam-se as seguintes seções: escopo, caracterização do projeto, inclusão de alternativas, diagnóstico ambiental, identificação de impactos, descrição dos impactos previstos, medidas mitigadoras, monitoramento, dificuldades técnicas e ausência de informações, participação social, apresentação dos resultados e RIMA.

A aplicação destes critérios se dá a partir da análise de seu elemento equivalente que integra o estudo, ou seja, por exemplo, considerando o elemento 'caracterização do projeto', se este não for considerado no estudo de impacto ambiental será automaticamente atribuído zero agora se este elemento for considerado, ele será avaliado em três faixas: (baixo, quando o elemento for considerado de forma incompleta e tecnicamente insatisfatório, médio, quando o elemento for considerado de forma razoável e satisfatório ou alto, quando o elemento for considerado completo e muito satisfatório). 
A escala empregada (tabela 5) para a revisão da qualidade do estudo de impacto ambiental varia de 0,0 a 3,0, não havendo diferenciação de pesos na ponderação dos critérios e subcritérios. Os resultados são agrupados em 6 categorias: 'Muito fraco' $(0,0-0,4)$, quando a maioria dos subcritérios (associada a cada critério) não foi contemplada e os demais o foram de maneira deficiente; 'Fraco' $(0,5$ - 0,9), quando uma quantidade significativa de subcritérios não foi contemplada e alguns outros apresentam deficiências; 'Regular' $(1,0$ - 1,4), quando parte dos subcritérios foi contemplada, mas outra parte permaneceu abaixo de padrões satisfatórios.

'Satisfatório' $(1,5$ - 1,9), quando apenas uma pequena parte dos subcritérios não foi contemplada, mas outra parte significativa atendeu níveis satisfatórios; Bom $(2,0-2,4)$, quando todos os subcritérios foram contemplados, e a maioria deles em um nível satisfatório. Por fim, tem-se 'Muito bom' $(2,5-3,0)$, quando todos os subcritérios foram contemplados satisfatoriamente. A qualidade geral do estudo analisado foi obtida no presente trabalho a partir da média calculada para o conjunto de critérios aplicados (MONTAÑO et al., 2014).

Tabela 1: Lista de Verificação para Avaliação da Qualidade do Estudo de Impacto Ambiental.

\begin{tabular}{|c|c|c|}
\hline Componentes & Sim & Não \\
\hline \multicolumn{3}{|l|}{ 1. Apresenta um sumário? } \\
\hline \multicolumn{3}{|l|}{ 2. Apresenta uma lista de quadros, figuras, fotos e anexos? } \\
\hline \multicolumn{3}{|l|}{ 3. Apresenta uma lista de siglas e abreviaturas? } \\
\hline \multicolumn{3}{|l|}{ 4. Apresenta um resumo? } \\
\hline \multicolumn{3}{|l|}{ 5. Apresenta introdução? } \\
\hline \multicolumn{3}{|l|}{ 6. Faz uma apresentação básica do empreendimento? } \\
\hline \multicolumn{3}{|l|}{ 7. Apresenta um resumo das características principais do empreendimento? } \\
\hline \multicolumn{3}{|l|}{ 8. Apresenta informação do termo de referência do empreendimento? } \\
\hline \multicolumn{3}{|l|}{ 9. Faz uma apresentação do estudo, estrutura e conteúdo em capítulos? } \\
\hline \multicolumn{3}{|l|}{ 10. Apresenta informações gerais sobre o empreendimento? } \\
\hline \multicolumn{3}{|l|}{ 11. Apresenta a localização e acessos do empreendimento? } \\
\hline \multicolumn{3}{|l|}{ 12. Faz uma apresentação da empresa proponente? } \\
\hline \multicolumn{3}{|l|}{ 13. Apresenta objetivo e justificativa do empreendimento? } \\
\hline \multicolumn{3}{|l|}{ 14. Apresenta histórico do empreendimento e das etapas de licenciamento? } \\
\hline \multicolumn{3}{|l|}{ 15. Faz análise da compatibilidade do empreendimento com a legislação incidente? } \\
\hline \multicolumn{3}{|l|}{ 16. Faz análise do empreendimento com programas governamentais? } \\
\hline \multicolumn{3}{|l|}{ 17. Apresenta uma descrição do empreendimento e suas alternativas? } \\
\hline \multicolumn{3}{|l|}{ 18. Apresenta as alternativas consideradas? } \\
\hline \multicolumn{3}{|c|}{ 19. Apresenta critérios de seleção e justificativa da escolha das alternativas? } \\
\hline \multicolumn{3}{|c|}{ 20. Apresenta atividades do empreendimento na etapa de desativação (quando aplicável)? } \\
\hline \multicolumn{3}{|c|}{ 21. Apresenta um cronograma do projeto? } \\
\hline \multicolumn{3}{|l|}{ 22. Apresenta o diagnóstico ambiental? } \\
\hline \multicolumn{3}{|l|}{ 23. Apresenta uma descrição da área de estudo? } \\
\hline \multicolumn{3}{|l|}{ 24. Apresenta o diagnóstico do meio físico? } \\
\hline \multicolumn{3}{|l|}{ 25. Apresenta o diagnóstico do meio biótico? } \\
\hline \multicolumn{3}{|l|}{ 26. Apresenta o diagnóstico do meio antrópico? } \\
\hline \multicolumn{3}{|l|}{ 27. Elabora a análise dos impactos ambientais? } \\
\hline \multicolumn{3}{|l|}{ 28. Apresenta a metodologia empregada na análise dos impactos ambientais? } \\
\hline 29. Faz identificação, previsão e avaliação dos impactos ambientais? & & \\
\hline 30. Apresenta uma síntese do prognóstico ambiental? & & \\
\hline 31. Apresenta um plano de gestão ambiental? & & \\
\hline 32. Apresenta as medidas mitigadoras e compensatórias? & & \\
\hline 33. Apresenta plano de recuperação de áreas degradadas? & & \\
\hline 34. Apresenta um programa de monitoramento e acompanhamento? & & \\
\hline 35. Apresenta um cronograma de implantação do programa ambiental? & & \\
\hline 36. Apresenta referências bibliográficas completas? & & \\
\hline 37. Apresenta a equipe técnica com a qualificação profissional de cada um? & & \\
\hline 38. Apresenta um glossário? & & \\
\hline
\end{tabular}




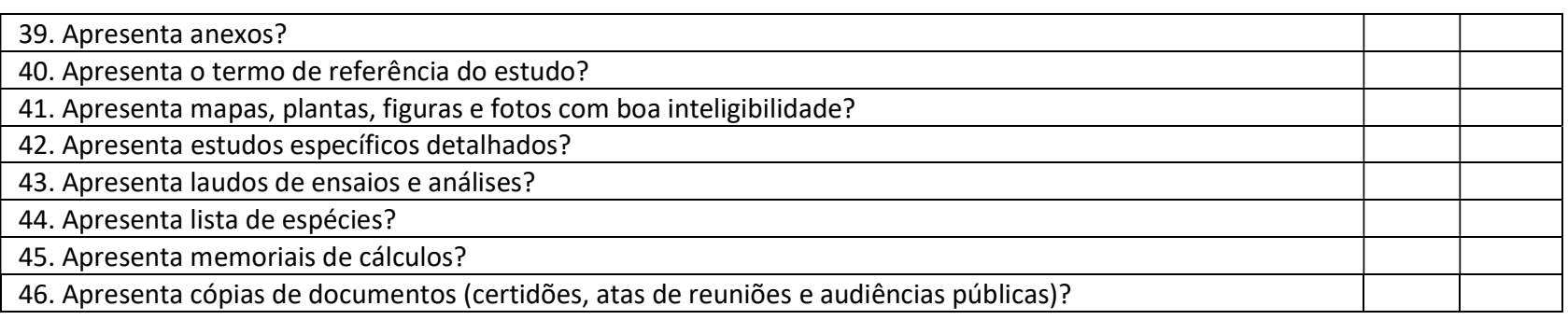

Tabela 2: Procedimento Lee and Colley Review Package para Avaliação da Qualidade do Estudo de Impacto Ambiental.

\section{Descrição do projeto e do ambiente afetado}

1.1. Descrição do projeto

1.1.1. Objetivos do projeto.

1.1.2. Design e tamanho do projeto.

1.1.3. Presença física do projeto no meio ambiente.

1.1.4. Natureza dos processos e taxa de produção.

1.1.5. Natureza e quantidade de matérias-primas.

1.2. Descrição do local

1.2.1. Descrição e localização da área.

1.2.2. Descrição e localização dos usos da terra.

1.2.3. Duração das fases do projeto.

1.2.4. Número de trabalhadores e meios de transporte.

1.2.5. Meios de transporte e quantidades de materiais.

1.3. Resíduos

1.3.1. Tipos e quantidades.

1.3.2. Tratamento e disposição.

1.3.3. Método de cálculo da estimativa de geração, possíveis incertezas e limites de confiança.

1.4. Descrição do ambiente

1.4.1. Indicação do ambiente afetado.

1.4.2. Área de influência indireta.

1.5. Condições da linha de base

1.5.1. Descrição dos componentes importantes, métodos e incertezas.

1.5.2. Fontes de dados existentes.

1.5.3. Prognóstico do local sem o empreendimento.

2. Identificação e avaliação de impactos-chave

2.1. Definição dos impactos

2.1.1. Tipos de impacto (diretos, indiretos, secundários, cumulativos, a curto, médio e longo prazos, permanentes e temporários, positivos e negativos).

2.1.2. Efeitos dos impactos e as interações entre eles.

2.1.3. Impactos de situações anormais.

2.1.4. Impactos com relação à linha de base (diferença entre as condições futuras com e sem o empreendimento).

2.2. Identificação dos impactos

2.2.1. Métodos utilizados.

2.2.2. Justificativa de uso dos métodos.

2.3. Escopo

2.3.1. Participação do público em geral e grupos de interesse.

2.3.2. Métodos de coleta de opiniões.

2.3.3. Investigação detalhada dos principais impactos. Justificativa das áreas não selecionadas para estudo.
2.4. Previsão da magnitude do impacto

2.4.1. Identificação e justificativa dos dados, lacunas e incertezas da avaliação.

2.4.2. Descrição e justificativa dos métodos.

2.4.3. Definição e justificativa dos parâmetros de avaliação.

2.5. Avaliação de significância dos impactos

2.5.1. Significância do impacto para a comunidade e o ambiente afetado.

2.5.2. Métodos utilizados.

2.5.3. Justificativa de normas, suposições e parâmetros utilizados.

3. Consideração de alternativas e medidas mitigadoras 3.1. Alternativas

3.1.1. Vantagens e desvantagens de alternativas locacionais viáveis e justificativas para a escolhida.

3.1.2. Alternativas tecnológicas.

3.1.3. Seleção de alternativas.

3.2. Escopo e efetividade das medidas mitigadoras

3.2.1. Medidas mitigadoras para os impactos adversos significativos. Descrição e justificativa para os impactos residuais.

3.2.2. Consideração de mudanças no projeto, compensação, instalações alternativas e controle.

3.2.3. Efetividade das medidas.

3.3. Compromisso com a mitigação

3.3.1. Detalhamento das medidas.

3.3.2. Sistema de monitoramento e ajuste das medidas.

4. Comunicação dos resultados

4.1. Layout

4.1.1. Introdução: os objetivos do projeto e da avaliação ambiental.

4.1.2. Apresentação lógica e organizada.

4.1.3. Resumo dos capítulos.

4.1.4. Referências.

4.2. Apresentação

4.2.1. Texto compreensível para não especialistas.

4.2.2. Definição de termos técnicos.

4.2.3. Texto contínuo e integrado.

4.3. Ênfase

4.3.1. Ênfase aos impactos significativos.

4.3.2 Imparcialidade do texto.

4.4. Resumo não técnico (RIMA)

4.3.3. Linguagem não técnica.

4.3.4. Principais questões do estudo e breve explicação sobre a confiabilidade dos métodos utilizados.

Tabela 3: Conceitos Estabelecidos pelo Procedimento Lee and Colley Review Package para Avaliação da Qualidade do Estudo de Impacto Ambiental.

\begin{tabular}{|c|c|}
\hline Conceito & Critério \\
\hline A & Bem realizado, nenhuma tarefa importante incompleta. \\
\hline B & Geralmente, satisfatório e completo, apenas omissões menores e poucos pontos inadequados. \\
\hline C & Satisfatório, apesar de omissões ou pontos inadequados. \\
\hline D & $\begin{array}{c}\text { Contém partes satisfatórias, mas o conjunto é considerado insatisfatório devido a omissões importantes ou pontos } \\
\text { inadequados. }\end{array}$ \\
\hline E & Insatisfatório, omissões ou pontos inadequados significativos. \\
\hline
\end{tabular}




\begin{tabular}{|c|c|}
\hline F & Muito insatisfatório, tarefas importantes desempenhadas de modo inadequado ou deixadas de lado. \\
\hline NA & Não aplicável. \\
\hline
\end{tabular}

Fonte: Lee et al. (1992).

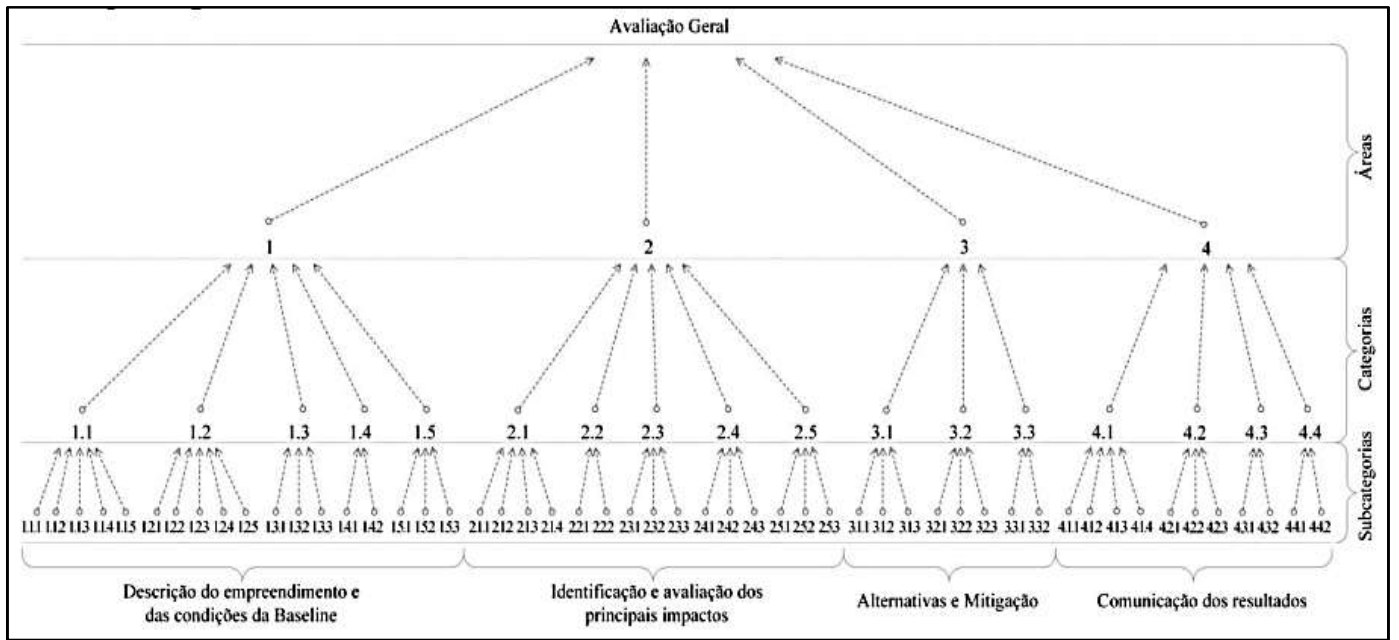

Figura 1: Disposição Hierárquica das Áreas, Categorias e Subcategorias do Procedimento para Avaliação da Qualidade do Estudo de Impacto Ambiental. Fonte: Lee et al. (1992).

Tabela 4: Critérios e Subcritérios do Procedimento para Avaliação da Qualidade do Estudo de Impacto Ambiental.

\begin{tabular}{|c|c|}
\hline Critérios & Subcritérios \\
\hline \multirow{4}{*}{ (1) “Scoping” (escopo) } & (1.1) Identifica os principais temas a serem analisados no relatório do EIA. \\
\hline & (1.2) Identifica adequadamente os impactos mais significativos. \\
\hline & (1.3) Envolve os principais atores no escopo do EIA. \\
\hline & (1.4) Descreve e justifica o escopo bem como os métodos utilizados. \\
\hline \multirow{6}{*}{$\begin{array}{l}\text { (2) Caracterização do } \\
\text { projeto }\end{array}$} & (2.1) Identifica e caracteriza os diferentes componentes do projeto. \\
\hline & $\begin{array}{l}\text { (2.2) Caracteriza as fases de construção, operação e desativação; descreve para cada fase os materiais, } \\
\text { a energia utilizada e produzida, os efluentes, resíduos e emissões produzidos. }\end{array}$ \\
\hline & $\begin{array}{l}\text { (2.3) Descreve a relação entre o projeto em âmbito local, regional e nacional que afetam o meio } \\
\text { ambiente circunvizinho. Diagramas, mapas e planos são utilizados com este objetivo. }\end{array}$ \\
\hline & $\begin{array}{l}\text { (2.4) Descreve a localização do projeto, os seus diferentes acessos e identifica as áreas sensíveis que } \\
\text { poderão ser mais afetadas. }\end{array}$ \\
\hline & (2.5) Inclui as razões pelas quais o projeto proposto foi escolhido. \\
\hline & (2.6) Descreve e explica os objetivos do projeto. \\
\hline \multirow{3}{*}{$\begin{array}{l}\text { (3) Inclusão de } \\
\text { alternativas }\end{array}$} & $\begin{array}{l}\text { (3.1) Apresenta uma avaliação objetiva de todas as alternativas razoáveis. Descreve as várias } \\
\text { alternativas em relação Á localização do projeto, componentes e processos tecnológicos disponíveis. }\end{array}$ \\
\hline & (3.2) Descreve a alternativa zero, ou seja, a opção de não implantação do projeto. \\
\hline & (3.3) Explica as razões pelas quais algumas alternativas foram descartadas do estudo. \\
\hline \multirow{4}{*}{$\begin{array}{l}\text { (4) Diagnóstico } \\
\text { ambiental }\end{array}$} & $\begin{array}{l}\text { (4.1) Caracteriza a situação ambiental que deve envolver a descrição e caracterização de todos os } \\
\text { fatores ambientais suscetíveis a serem afetados. }\end{array}$ \\
\hline & $\begin{array}{l}\text { (4.2) Descreve a metodologia para caracterizar cada fator ambiental e os métodos usados para realizar } \\
\text { todos os estudos analíticos. }\end{array}$ \\
\hline & $\begin{array}{l}\text { (4.3) Inclui informação quantitativa sempre que necessária e bases cartográficas para a melhor } \\
\text { compreensão/interpretação dos dados; apresenta justificativas científicas, sempre que necessário. }\end{array}$ \\
\hline & $\begin{array}{l}\text { (4.4) Inclui a caracterização do patrimônio histórico e arqueológico e todos os aspectos } \\
\text { socioeconômicos relevantes. }\end{array}$ \\
\hline \multirow{2}{*}{$\begin{array}{l}\text { (5) Identificação de } \\
\text { impactos }\end{array}$} & $\begin{array}{l}\text { (5.1) Identifica as principais ações capazes de gerar impactos em todas as fases do projeto, e aquelas } \\
\text { que podem alterar processos naturais. }\end{array}$ \\
\hline & $\begin{array}{l}\text { (5.2) Identifica os impactos do projeto para cada e qualquer fator ambiental selecionado, nas diferentes } \\
\text { fases do projeto, utilizando os dados fornecidos pela pesquisa e análise das condições da área e das } \\
\text { características do projeto. }\end{array}$ \\
\hline \multirow{4}{*}{$\begin{array}{l}\text { (6) Descrição dos } \\
\text { impactos previstos }\end{array}$} & $\begin{array}{l}\text { (6.1) Apresenta a metodologia para a predição de impacto e avaliação científica e indica a incerteza } \\
\text { associada a cada predição; os métodos utilizados devem ser explicados e as razões para escolha do } \\
\text { nível de detalhe da análise devem ser fornecidas. }\end{array}$ \\
\hline & $\begin{array}{l}\text { (6.2) identifica outros impactos que possam ocorrer após a implementação das medidas de } \\
\text { minimização, e avalia os impactos que possam ocorrer devido às condições anormais. }\end{array}$ \\
\hline & $\begin{array}{l}\text { (6.3) Evita a introdução de julgamentos subjetivos de valor e a imposição da opinião dos atores } \\
\text { envolvidos sobre a importância dos impactos ambientais ou sociais }\end{array}$ \\
\hline & $\begin{array}{l}\text { (6.4) Avalia os impactos de acordo com sua importância relativa, isto é, em relação às características } \\
\text { do impacto tais como a área de influência, o tipo, a natureza, magnitude, duração, reversibilidade e } \\
\text { probabilidade de ocorrência. }\end{array}$ \\
\hline
\end{tabular}




\begin{tabular}{|c|c|}
\hline & $\begin{array}{l}\text { (6.5) Caracteriza as relações de causa-efeito de cada impacto ambiental; avaliação retroativa, impactos } \\
\text { cumulativos e sinérgicos. }\end{array}$ \\
\hline \multirow{4}{*}{$\begin{array}{l}\text { (7) Medidas } \\
\text { mitigadoras }\end{array}$} & $\begin{array}{l}\text { (7.1) Descreve as medidas de mitigação ou compensação propostas, com informações relativas à sua } \\
\text { aplicação e eficácia. }\end{array}$ \\
\hline & $\begin{array}{l}\text { (7.2) Fornece evidências do empenho do proponente e sua capacidade para implementar as medidas } \\
\text { mitigadoras. }\end{array}$ \\
\hline & $\begin{array}{l}\text { (7.3) Justifica, quando for o caso, a ausência de propostas de mitigação para os impactos significativos } \\
\text { previamente identificados. }\end{array}$ \\
\hline & $\begin{array}{l}\text { (7.4) Propõe um programa de monitoramento sempre que existir incerteza sobre os resultados práticos } \\
\text { de uma medida mitigadora, permitindo ajustes futuros, se necessário. }\end{array}$ \\
\hline \multirow{5}{*}{ (8) Monitoramento } & (8.1) Descreve os objetivos do programa de monitoramentos e sua justificativa científica. \\
\hline & $\begin{array}{l}\text { (8.2) Descreve com precisão quais tipos de indicadores devem ser monitorados, como e quando devem } \\
\text { ser monitorados e que organização/instituição deve ser responsável pela fiscalização. }\end{array}$ \\
\hline & (8.3) Fornece evidências do compromisso dos proponentes com o(s) programa(s) de monitoramento. \\
\hline & (8.4) identifica outros agentes envolvidos e os papéis específicos desses agentes, se aplicável. \\
\hline & (8.5) Justifica a escolha dos programas de monitoramento para todos os fatores ambientais. \\
\hline $\begin{array}{l}\text { (9) Dificuldades } \\
\text { técnicas e ausência de } \\
\text { informações }\end{array}$ & $\begin{array}{l}\text { (9.1) Identifica as limitações e dificuldades enfrentadas pela equipe técnica durante a preparação do } \\
\text { relatório de EIA. }\end{array}$ \\
\hline \multirow{4}{*}{ (10) Participação social } & (10.1) Identifica os grupos de interesse e o público em geral envolvido na consulta. \\
\hline & $\begin{array}{l}\text { (10.2) Incorpora a multiplicidade de valores fornecidos pelo público, especialistas e grupos de } \\
\text { interesse; descreve as ações que foram tomadas para determinar a opinião das populações locais em } \\
\text { relação às consequências sociais dos impactos previstos. Fornece evidência de consideração das } \\
\text { percepções e opiniões da comunidade. }\end{array}$ \\
\hline & (10.3) Fornece razões explícitas do porquê certas sugestões não foram incorporadas ao EIA. \\
\hline & (10.4) Identifica o grau de preocupação ou de conflito com o público. \\
\hline \multirow[t]{5}{*}{$\begin{array}{l}\text { (11) Apresentação dos } \\
\text { resultados }\end{array}$} & $\begin{array}{l}\text { (11.1) Apresenta um estudo claro, coerentemente organizado, bem escrito e facilmente compreensível } \\
\text { por não especialistas e pelo público; fontes de informação são mencionadas de forma clara; qualquer } \\
\text { informação, dados ou abordagens provenientes de fontes externas são devidamente apoiadas por uma } \\
\text { referência; inclui uma lista completa de referências. }\end{array}$ \\
\hline & $\begin{array}{l}\text { (11.2) Indica que grupo de disciplinas técnicas e científicas tem orientado a preparação do estudo; } \\
\text { informa que a legislação/regulamentação foi atendida adequadamente. }\end{array}$ \\
\hline & $\begin{array}{l}\text { (11.3) Termos técnicos são explicados detalhadamente no glossário ou em texto; os pareceres e } \\
\text { relatórios dos peritos são complementados com uma interpretação adequada e não apenas anexados } \\
\text { ao estudo. }\end{array}$ \\
\hline & (11.4) Indica os nomes e qualificação da equipe técnica. \\
\hline & $\begin{array}{l}\text { (11.5) Apresenta as conclusões finais sobre os impactos positivos e negativos da proposta, } \\
\text { considerando as diferentes fases do projeto. }\end{array}$ \\
\hline \multirow{4}{*}{ (12) RIMA } & $\begin{array}{l}\text { (12.1) Inclui um resumo adequado não técnico (RIMA), que descreve a constituição geral do projeto e } \\
\text { brevemente caracteriza a construção, operação e desativação. }\end{array}$ \\
\hline & $\begin{array}{l}\text { (12.2) Identifica os principais fatores ambientais a serem afetados pelo projeto, suas alternativas, seus } \\
\text { principais impactos e as propostas de mitigação/compensação. }\end{array}$ \\
\hline & $\begin{array}{l}\text { (12.3) É claro, conciso e bem escrito, sem excessos ou linguagem técnica ou estatística complexa. } \\
\text { Reflete o conteúdo geral do EIA e apresenta as suas principais conclusões, suas alternativas e medidas } \\
\text { mitigadoras e como serão alcançadas. }\end{array}$ \\
\hline & (12.4) Indica os planos de monitoramento proposto no EIA. \\
\hline
\end{tabular}

Fonte: Pinho et al. (2007).

Tabela 5: Conceitos para Avaliação da Qualidade do Estudo de Impacto Ambiental.

\begin{tabular}{|c|c|c|}
\hline Qualidade & Critério & Conceito \\
\hline I & Muito fraco & $(0,0-0,4)$ \\
\hline II & Fraco & $(0,5-0,9)$ \\
\hline III & Regular & $(1,0-1,4)$ \\
\hline IV & Satisfatorio & $(2,0-2,4)$ \\
\hline V & Bom & $(2,5-3,0)$ \\
\hline VI & Muito bom & \\
\hline
\end{tabular}

Fonte: Pinho et al. (2007).

\section{RESULTADOS E DISCUSSÃO}

O estudo de impacto ambiental selecionado caracteriza-se por um empreendimento do setor de energia com exploração de gás natural e implantação prevista no litoral paulista. No estudo de impacto ambiental do empreendimento, foi possível verificar a apresentação de três alternativas locacionais e após 
análise técnica-operacional e socioambiental, o empreendimento definiu-se pela viabilidade de uma delas, apresentando sua justifica para tal escolha. $O$ estudo também caracterizou as áreas de influência do empreendimento (área de influência direta (AID), área de influência indireta (AII) e área diretamente afetada $(A D A))$.

A tabela 6 apresenta os principais impactos ambientais mensurados no estudo, destacando-se incômodos a população, perda de cobertura vegetal, perda de habitat para a fauna terrestre, afugentamento da fauna terrestre, interferências em serviços públicos, dinamização da economia, interferências na atividade de pesca, interferências em atividades econômicas e desapropriações e realocações.

A tabela 7 mostra os programas ambientais de mitigação e compensação dos impactos ambientais do empreendimento, destacando-se os programas relacionados a qualidade do ar (emissões atmosféricas), qualidade das águas e sedimentos, compensação florestal, monitoramento da fauna terrestre e aquática, educação ambiental e socioeconômicos com fomentos a atividades de turismo e pesca e apoios municipais. O estudo apontou a ocorrência de potenciais 46 impactos, sendo destes 36 (78\%) considerados negativos enquanto $10(22 \%)$ considerados positivos. Considerando os impactos ambientais negativos, 13 (36\%) foram considerados de significância alta. $\mathrm{O}$ estudo conclui que o empreendimento proposto é ambientalmente viável.

Tabela 6: Síntese dos Impactos Ambientais do Empreendimento.

\begin{tabular}{|l|l|c|c|}
\hline \multicolumn{1}{|c|}{ Meio } & \multicolumn{1}{|c|}{ Identificação do Impacto } & \multicolumn{2}{|c|}{ Avaliação dos Impactos } \\
\hline \multirow{5}{*}{ Físico } & \multicolumn{2}{|c|}{ Natureza } & Significância \\
\hline \multirow{5}{*}{ Biológico } & Processos erosivos & Negativa & Média \\
\cline { 2 - 4 } & Alteração da qualidade da água & Negativa & Média \\
\cline { 2 - 4 } & Incômodos à população & Negativa & Alta \\
\hline & Perda da cobertura vegetal & Negativa & Baixa \\
\cline { 2 - 4 } & Alteração da biota aquática & Negativa & Alta \\
\cline { 2 - 4 } & Perda de habitat para a fauna & Negativa & Média \\
\cline { 2 - 4 } & Perda de espécimes da fauna & Negativa & Baixa \\
\cline { 2 - 4 } & Aumento da pressão de caça & Negativa & Alta \\
\cline { 2 - 4 } & Afugentamento da fauna & Negativa & Média \\
\cline { 2 - 4 } & Interferências em áreas protegidas & Negativa & Média \\
\hline \multirow{5}{*}{ Socioeconômico } & Alteração da paisagem & Negativa & Alta \\
\cline { 2 - 4 } & Interferências em serviços públicos & Positiva & Alta \\
\cline { 2 - 4 } & Dinamização da economia & Positiva & Média \\
\cline { 2 - 4 } & Aumento da arrecadação municipal & Negativa & Média \\
\cline { 2 - 4 } & Alterações do setor de turismo & Negativa & Alta \\
\cline { 2 - 4 } & Interferências na atividade de pesca & Negativa & Alta \\
\cline { 2 - 4 } & Interferências em atividades econômicas & Negativa & Baixa \\
\cline { 2 - 4 } & Interferências no tráfego de embarcações & Negativa & Alta \\
\cline { 2 - 4 } & Desapropriações e realocações & Negativa & Média \\
\cline { 2 - 4 } & Interferências em patrimônios culturais & Média \\
\cline { 2 - 4 } & Alterações nas condições de segurança & \\
\hline
\end{tabular}

Tabela 7: Síntese dos Programas Ambientais do Empreendimento.

\begin{tabular}{|l|}
\hline \multicolumn{1}{|c|}{ Planos e Programas Ambientais } \\
\hline 1. Plano de gerenciamento ambiental de obras \\
1.1. Programa de controle de poluição de canteiros e frente de obras \\
1.2. Programa de controle de processos erosivos e assoreamento \\
1.3. Programa de controle de supressão de vegetação \\
1.4. Programa de resgate e salvamento de fauna terrestre \\
1.5. Programa de gerenciamento ambiental de obras de dragagem \\
1.6. Programa de controle de tráfego \\
1.7. Programa de monitoramento da qualidade das águas e sedimentos
\end{tabular}


1.8. Programa de monitoramento da qualidade das águas subterrâneas

1.9. Programa de monitoramento da qualidade do ar

1.10. Programa de monitoramento de ruído

1.11. Programa de monitoramento de atividades minerárias

1.12. Programa de negociação e indenização

2. Programa de gerenciamento de resíduos sólidos

3. Programa de gerenciamento de efluentes líquidos

4. Programa de gerenciamento de riscos

5. Plano de gestão ambiental da operação

6. Programa de manutenção da faixa de servidão da linha de transmissão

7. Programa de gestão da qualidade do ar (emissões atmosféricas e condições meteorológicas)

8. Programa de monitoramento das águas marinhas

9. Programa de compensação florestal

10. Programa de monitoramento e conservação da fauna (terrestre e aquática)

11. Programa de comunicação social integrada

12. Programa de educação ambiental

13. Programa de mobilização, desmobilização e capacitação de mão-de-obra

14. Programa de desenvolvimento de fornecedores locais

15. Programa de fomento à atividade turística

16. Programa de reforço da infraestrutura municipal

17. Programa de compensação de atividade pesqueira

O primeiro critério avaliado se caracteriza mais pela análise estrutural do estudo de impacto ambiental. Com base na listagem de verificação proposta por Sánchez $(2006,2013)$, chegou-se ao resultado de que o estudo do empreendimento atendeu de maneira muito satisfatória este critério, pois a maioria dos requisitos estabelecidos foi atendida. Tal constatação pode ser observada na tabela 8 . Somente alguns poucos critérios não foram atendidos, entretanto são critérios que não comprometem a estrutura geral do estudo de impacto ambiental. Este resultado inicial é positivo, uma vez que se atesta na literatura a existência de deficiências quanto à organização e apresentação do estudo de impacto ambiental.

Tabela 8: Avaliação do Estudo de Impacto Ambiental.

\begin{tabular}{|c|c|c|}
\hline Componentes & Sim & Não \\
\hline 1. Apresenta um sumário? & $\mathrm{X}$ & \\
\hline 2. Apresenta uma lista de quadros, figuras, fotos e anexos? & $\mathrm{X}$ & \\
\hline 3. Apresenta uma lista de siglas e abreviaturas? & & $\mathrm{x}$ \\
\hline 4. Apresenta um resumo? & $X$ & \\
\hline 5. Apresenta introdução? & $\mathrm{X}$ & \\
\hline 6. Faz uma apresentação básica do empreendimento? & $\mathrm{X}$ & \\
\hline 7. Apresenta um resumo das características principais do empreendimento? & $\mathrm{X}$ & \\
\hline 8. Apresenta informação do termo de referência do empreendimento? & $\mathrm{X}$ & \\
\hline 9. Faz uma apresentação do estudo, estrutura e conteúdo em capítulos? & $\mathrm{X}$ & \\
\hline 10. Apresenta informações gerais sobre o empreendimento? & $\mathrm{X}$ & \\
\hline 11. Apresenta a localização e acessos do empreendimento? & $\mathrm{X}$ & \\
\hline 12. Faz uma apresentação da empresa proponente? & $\mathrm{X}$ & \\
\hline 13. Apresenta objetivo e justificativa do empreendimento? & $\mathrm{x}$ & \\
\hline 14. Apresenta histórico do empreendimento e das etapas de licenciamento? & $\mathrm{X}$ & \\
\hline 15. Faz análise da compatibilidade do empreendimento com a legislação incidente? & $\mathrm{X}$ & \\
\hline 16. Faz análise do empreendimento com programas governamentais? & $\mathrm{X}$ & \\
\hline 17. Apresenta uma descrição do empreendimento e suas alternativas? & $\mathrm{X}$ & \\
\hline 18. Apresenta as alternativas consideradas? & $\mathrm{X}$ & \\
\hline 19. Apresenta critérios de seleção e justificativa da escolha das alternativas? & $\mathrm{X}$ & \\
\hline $\begin{array}{l}\text { 20. Apresenta atividades e componentes do empreendimento nas etapas de implantação, operação e desativação } \\
\text { (quando aplicável)? }\end{array}$ & $\mathrm{X}$ & \\
\hline 21. Apresenta um cronograma do projeto? & $\mathrm{X}$ & \\
\hline 22. Apresenta o diagnóstico ambiental? & $\mathrm{x}$ & \\
\hline 23. Apresenta uma descrição da área de estudo? & $\mathrm{X}$ & \\
\hline 24. Apresenta o diagnóstico do meio físico? & $\mathrm{x}$ & \\
\hline 25. Apresenta o diagnóstico do meio biótico? & $\mathrm{X}$ & \\
\hline 26. Apresenta o diagnóstico do meio antrópico? & $\mathrm{x}$ & \\
\hline
\end{tabular}




\begin{tabular}{|c|c|c|}
\hline 27. Elabora a análise dos impactos ambientais? & $\mathrm{X}$ & \\
\hline 28. Apresenta a metodologia empregada na análise dos impactos ambientais? & $\mathrm{X}$ & \\
\hline 29. Faz identificação, previsão e avaliação dos impactos ambientais? & $\mathrm{x}$ & \\
\hline 30. Apresenta uma síntese do prognóstico ambiental? & & $\mathrm{X}$ \\
\hline 31. Apresenta um plano de gestão ambiental? & $\mathrm{X}$ & \\
\hline 32. Apresenta as medidas mitigadoras e compensatórias? & $\mathrm{X}$ & \\
\hline 33. Apresenta plano de recuperação de áreas degradadas? & $\mathrm{X}$ & \\
\hline 34. Apresenta um programa de monitoramento e acompanhamento? & $\mathrm{X}$ & \\
\hline 35. Apresenta um cronograma de implantação do programa ambiental? & $\mathrm{X}$ & \\
\hline 36. Apresenta referências bibliográficas completas? & $\mathrm{X}$ & \\
\hline 37. Apresenta a equipe técnica com a qualificação profissional de cada um? & $\mathrm{X}$ & \\
\hline 38. Apresenta um glossário? & & $X$ \\
\hline 39. Apresenta anexos? & $\mathrm{X}$ & \\
\hline 40. Apresenta o termo de referência do estudo? & $\mathrm{X}$ & \\
\hline 41. Apresenta mapas, plantas, figuras e fotos com boa inteligibilidade? & $\mathrm{X}$ & \\
\hline 42. Apresenta estudos específicos detalhados? & & $\mathrm{X}$ \\
\hline 43. Apresenta laudos de ensaios e análises? & $\mathrm{X}$ & \\
\hline 44. Apresenta lista de espécies? & $\mathrm{X}$ & \\
\hline 45. Apresenta memoriais de cálculos? & & $\mathrm{X}$ \\
\hline 46. Apresenta cópias de documentos (certidões, atas de reuniões e audiências públicas)? & & $\mathrm{x}$ \\
\hline
\end{tabular}

Fonte: Sánchez $(2006,2013)$.

O segundo critério avaliado caracteriza-se pela análise de conteúdo do estudo de impacto ambiental. A tabela 9 mostra os resultados obtidos da avaliação da técnica proposta por Lee et al. (1992). Os resultados mostram que as 4 áreas do estudo de impacto ambiental foram executadas satisfatoriamente, pois receberam notas entre $\mathrm{B}$ e C, ou seja, foi detectado apenas omissões menores e poucos pontos inadequados. Em relação às categorias, a imensa maioria dos critérios recebeu nota entre A e C. Portanto, podemos considerar que os itens foram satisfatórios também.

Somente o critério 4.3 das categorias recebeu nota $D$, portanto este foi considerado insatisfatório, devido a omissões e pontos inadequados significativos. Este critério refere-se ao item 'Ênfase', que se caracteriza com base na ênfase dos impactos ambientais e imparcialidade do texto no estudo, assim julgouse que neste item o estudo não atendeu satisfatoriamente tais critérios (tabela 9). Quanto às subcategorias, algumas (1.3.3, 3.2 .3 e 4.3.2) receberam nota D (insatisfatórias), respectivamente Área 1: descrição do projeto e ambiente afetado; Área 3: consideração de alternativas e medidas mitigadoras; e Área 4: comunicação dos resultados). Uma recebeu nota E: a Área 2 (Identificação e avaliação de impactos-chave, item 2.1.3.

Tabela 9: Avaliação do Estudo de Impacto Ambiental.

\begin{tabular}{|c|c|c|c|c|c|c|}
\hline \multicolumn{7}{|c|}{ Avaliação Geral } \\
\hline \multicolumn{7}{|c|}{ Áreas } \\
\hline \multicolumn{2}{|l|}{$1(\mathrm{~B})$} & $2(B)$ & \multicolumn{2}{|l|}{$3(\mathrm{~B})$} & \multicolumn{2}{|l|}{$4(C)$} \\
\hline \multicolumn{7}{|c|}{ Categorias e Subcategorias } \\
\hline 1.1 & $B$ & 2.1 & 3.1 & $B$ & 4.1 & A \\
\hline 1.1 .1 & A & 2.1 .1 & 3.1 .1 & A & 4.1 .1 & B \\
\hline 1.1 .2 & A & 2.1.2 & 3.1 .2 & B & 4.1 .2 & A \\
\hline 1.1.3 & B & 2.1 .3 & 3.1 .3 & C & 4.1 .3 & A \\
\hline 1.1 .4 & A & 2.1.4 & & & 4.1.4 & A \\
\hline 1.1 .5 & B & & & & & \\
\hline 1.2 & $B$ & $2.2 \mathrm{~A}$ & 3.2 & $C$ & 4.2 & $\mathrm{C}$ \\
\hline 1.2 .1 & A & 2.2.1 A & 3.2 .1 & B & 4.2 .1 & C \\
\hline 1.2 .2 & A & $2.2 .2 \mathrm{~A}$ & 3.2 .2 & B & 4.2 .2 & C \\
\hline 1.2 .3 & B & & 3.2 .3 & D & 4.2 .3 & C \\
\hline 1.2 .4 & C & & & & & \\
\hline 1.2 .5 & B & & & & & \\
\hline
\end{tabular}




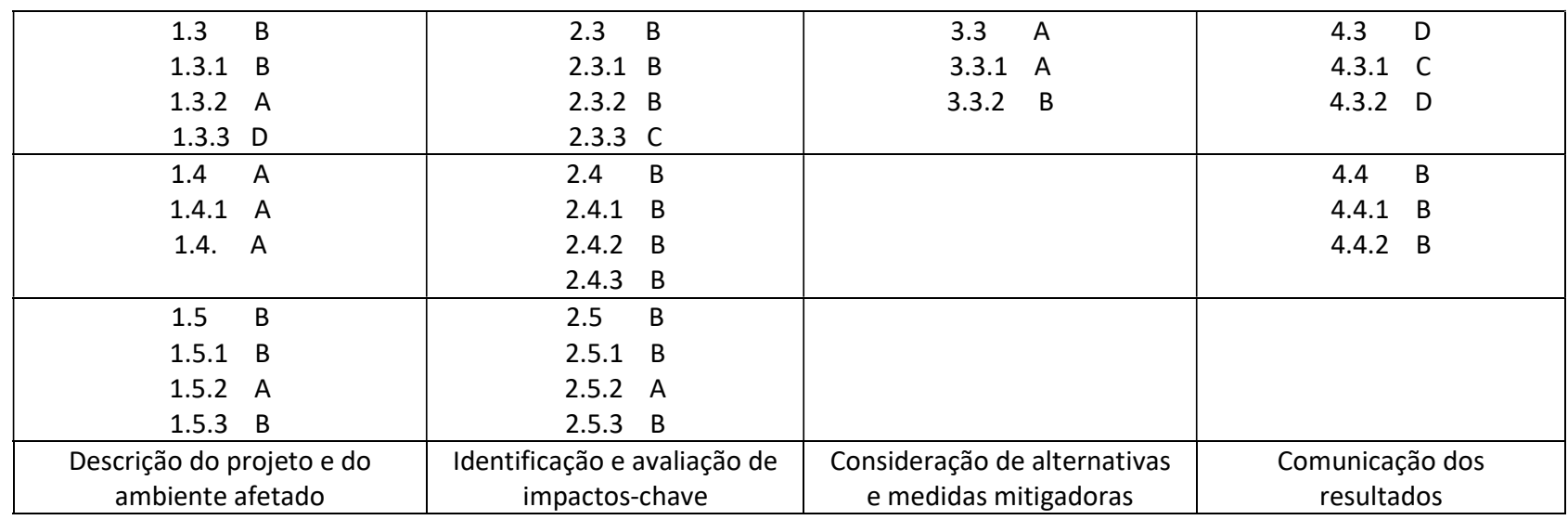

Fonte: Lee et al. (1992).

A tabela 10 apresenta todas as notas atribuídas às áreas, categorias e subcategorias utilizando uma escala de cor em função da nota, mostrando os critérios fortes e fracos do estudo de impacto ambiental avaliado. Os critérios da Área 1 (descrição do empreendimento e do ambiente afetado) somam 24 critérios; destes a 10 (cerca de 42\%), foi atribuída a nota A, 12 (50\%) a nota B, 1 (cerca de 4\%) a nota C e 1 (cerca de 4\%) a nota D. Já os critérios da Área 2 (identificação e avaliação de impactos-chave) somam 21 critérios; destes a 5 (cerca de 24\%), foi atribuída a nota A, 13 (cerca de 62\%) a nota B, 2 (cerca de 10\%) a nota C e 1 (cerca de 4\%) a nota $\mathrm{E}$.

Os critérios da Área 3 (consideração de alternativas e medidas mitigadoras) somam 12 critérios, destes a $3(25 \%)$ foi atribuído a nota A, 6 (50\%) a nota B, 2 (cerca de 17\%) a nota C e 1 (cerca de 8\%) a nota D. Considerando todos os critérios da Área 4 (comunicação dos resultados) estes somam 16 critérios, e destes 4 (25\%) foi atribuído a nota A, 4 (25\%) a nota B, 6 (cerca de 38\%) a nota C e 2 (cerca de 12\%) a nota D. Todos os critérios (73 itens) do procedimento de Lee et al. (1992), a 23 (cerca de 32\%) foi atribuída a nota A, 36 (cerca de $49 \%$ ) a nota B, $9(12 \%)$ a nota C, 4 (cerca de 5,6\%) a nota D e $1(1,4 \%)$ a nota E.

Em termos de desempenho por áreas, ainda que tenham sido identificados pontos fracos em itens de todas, os resultados indicam um pior desempenho relacionado à Área 4 (Comunicação dos resultados), que envolve a apresentação, ênfase aos impactos significativos e imparcialidade na escrita do estudo, aspectos relacionados a divulgação dos resultados as partes interessadas, relatório de impacto ambiental, audiência pública e participação popular.

Com base nesta ferramenta de análise, chegou-se ao resultado de que o estudo de impacto ambiental deste empreendimento é satisfatório (maior parte dos critérios recebeu nota entre $A$ e $C$ ), apesar da existência de pontos inadequados e omissões, sobretudo em relação à Área 4, comunicação dos resultados, fato que é preocupante no tocante a imparcialidade e idoneidade do estudo.

Mas não é só isto. Foi possível detectar no estudo diversas omissões de potenciais impactos ambientais e socioeconômicos, principalmente pelo fato de que o empreendimento apresenta previsão de instalação em áreas frágeis do ponto de vista ambiental, como ambientes ocupados por restinga e manguezal. Além dos impactos negativos associados a unidades de conservação presentes na região, riscos ambientais relacionados a vazamentos de combustíveis, poluição aquática de águas doce e marinha e impacto a biodiversidade em geral (riscos de extinções de espécies endêmicas), etc.. 
Tabela 10: Notas Atribuídas ao Estudo de Impacto Ambiental.

\begin{tabular}{|c|c|}
\hline \multirow{24}{*}{$\begin{array}{l}\text { Área } 1 \\
\text { Descrição do projeto e do ambiente afetado }\end{array}$} & 1. \\
\hline & 1.1. \\
\hline & 1.1.1. \\
\hline & 1.1.2. \\
\hline & 1.1.3. \\
\hline & 1.1.4. \\
\hline & 1.1.5. \\
\hline & 1.2 \\
\hline & 1.2.1. \\
\hline & 1.2.2. \\
\hline & 1.2.3. \\
\hline & 1.2.4. \\
\hline & 1.2.5. \\
\hline & 1.3 \\
\hline & 1.3.1. \\
\hline & 1.3.2. \\
\hline & 1.3.3. \\
\hline & 1.4. \\
\hline & 1.4.1. \\
\hline & 1.4.2. \\
\hline & 1.5. \\
\hline & 1.5.1. \\
\hline & 1.5.2. \\
\hline & 1.5.3. \\
\hline \multirow{21}{*}{$\begin{array}{l}\text { Área } 2 \\
\text { Identificação e avaliação de impactos-chave }\end{array}$} & 2. \\
\hline & 2.1 \\
\hline & 2.1.1. \\
\hline & 2.1.2. \\
\hline & 2.1.3. \\
\hline & 2.1.4. \\
\hline & 2.2 \\
\hline & 2.2.1. \\
\hline & 2.2.2. \\
\hline & 2.3 \\
\hline & 2.3.1. \\
\hline & 2.3.2. \\
\hline & 2.3.3. \\
\hline & 2.4 \\
\hline & 2.4.1. \\
\hline & 2.4.2. \\
\hline & 2.4.3. \\
\hline & 2.5 \\
\hline & 2.5.1. \\
\hline & 2.5.2. \\
\hline & 2.5.3. \\
\hline \multirow{12}{*}{$\begin{array}{l}\text { Área } 3 \\
\text { Consideração de alternativas e medidas mitigadoras }\end{array}$} & 3. \\
\hline & 3.1 \\
\hline & 3.1.1. \\
\hline & 3.1.2. \\
\hline & 3.1.3. \\
\hline & 3.2 \\
\hline & 3.2.1. \\
\hline & 3.2.2. \\
\hline & 3.2.3. \\
\hline & 3.3 \\
\hline & 3.3.1. \\
\hline & 3.3.2. \\
\hline \multirow{6}{*}{$\begin{array}{l}\text { Área } 4 \\
\text { Comunicação dos resultados }\end{array}$} & 4. \\
\hline & 4.1 \\
\hline & 4.1.1. \\
\hline & 4.1.2. \\
\hline & 4.1.3. \\
\hline & 4.1.4. \\
\hline
\end{tabular}




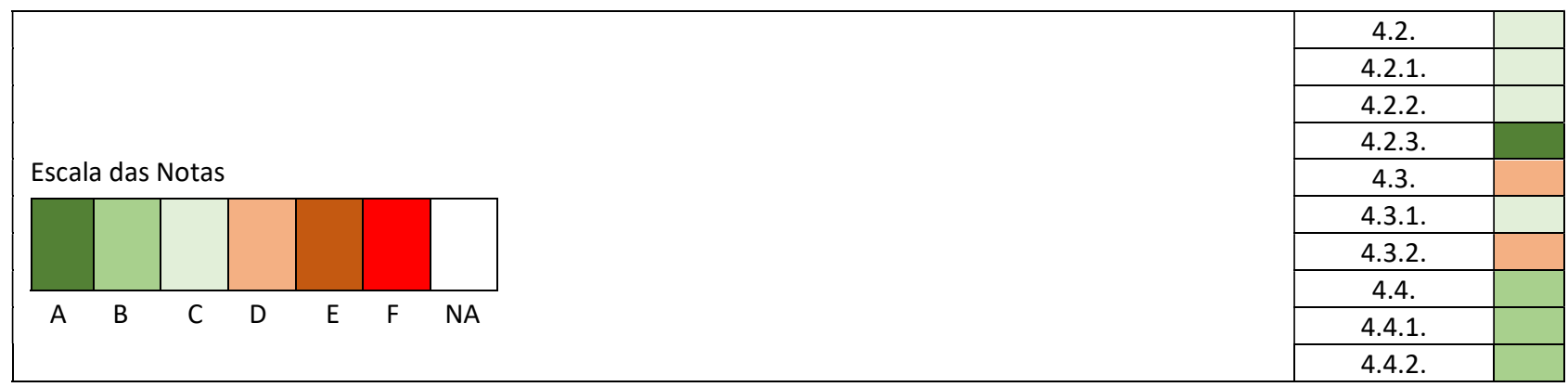

Fonte: Lee et al. (1992).

A tabela 11 mostra os resultados obtidos da aplicação do terceiro critério, proposto por Pinho et al. (2007). Analisando no geral as pontuações dos critérios é possível observar a ocorrência de 3 (25\%) critérios com classificação 'muito bom' (escopo, caracterização do projeto e inclusão de alternativas); 4 (cerca de 34\%) critérios (diagnóstico ambiental, monitoramento, apresentação dos resultados e RIMA) 'bom'; 3 critérios (25\%) (identificação de impactos, descrição dos impactos previstos e medidas mitigadoras) 'satisfatório'; 1 (8\%) critério (participação social) 'regular'; e 1 (8\%) critério (dificuldades técnicas e ausência de informações) 'muito fraco' (quadro 11). A partir da média aritmética considerando todos os critérios e subcritérios, o resultado obtido para o estudo avaliado foi de satisfatório (valor 1,9) (tabela 11).

Tabela 11: Análise do Estudo de Impacto Ambiental.

\begin{tabular}{|c|c|c|c|c|}
\hline Critérios & Subcritérios & Nota & Qualidade & Geral \\
\hline \multirow{4}{*}{ "Scoping" (escopo) } & $(1.1)$ & 2,5 & Muito bom & \multirow{4}{*}{$\begin{array}{c}2,5 \\
\text { Muito bom }\end{array}$} \\
\hline & $(1.2)$ & 2,4 & Bom & \\
\hline & $(1.3)$ & 2,4 & Bom & \\
\hline & (1.4) & 2,7 & Muito bom & \\
\hline \multirow{6}{*}{$\begin{array}{l}\text { Caracterização do } \\
\text { projeto }\end{array}$} & $(2.1)$ & 2,9 & Muito bom & \multirow{6}{*}{$\begin{array}{c}2,5 \\
\text { Muito bom }\end{array}$} \\
\hline & $(2.2)$ & 2,0 & Bom & \\
\hline & $(2.3)$ & 2,4 & Bom & \\
\hline & (2.4) & 2,3 & Bom & \\
\hline & (2.5) & 2,6 & Muito bom & \\
\hline & $(2.6)$ & 2,7 & Muito bom & \\
\hline \multirow[t]{3}{*}{ Inclusão de alternativas } & (3.1) & 2,5 & Muito bom & \multirow{3}{*}{$\begin{array}{c}2,5 \\
\text { Muito bom }\end{array}$} \\
\hline & (3.2) & 2,2 & Bom & \\
\hline & (3.3) & 2,7 & Muito bom & \\
\hline \multirow{4}{*}{ (4) Diagnóstico ambiental } & (4.1) & 2,2 & Bom & \multirow{4}{*}{$\begin{array}{c}2,4 \\
\text { Bom }\end{array}$} \\
\hline & $(4.2)$ & 2,4 & Bom & \\
\hline & (4.3) & 2,6 & Muito bom & \\
\hline & (4.4) & 2,6 & Muito bom & \\
\hline \multirow[t]{2}{*}{ (5) Identificação de impactos } & $(5.1)$ & 1,6 & Satisfatorio & \multirow{2}{*}{$\begin{array}{c}1,8 \\
\text { Satisfatório }\end{array}$} \\
\hline & $(5.2)$ & 2,0 & Bom & \\
\hline \multirow{5}{*}{$\begin{array}{l}\text { (6) Descrição dos impactos } \\
\text { previstos }\end{array}$} & (6.1) & 2,2 & Bom & \multirow{5}{*}{$\begin{array}{c}1,7 \\
\text { Satisfatório }\end{array}$} \\
\hline & $(6.2)$ & 1,5 & Satisfatorio & \\
\hline & (6.3) & 0,5 & Fraco & \\
\hline & $(6.4)$ & 2,7 & Muito bom & \\
\hline & (6.5) & 1,5 & Satisfatorio & \\
\hline \multirow{4}{*}{ (7) Medidas mitigadoras } & (7.1) & 2,4 & Bom & \multirow{4}{*}{$\begin{array}{c}1,8 \\
\text { Satisfatório }\end{array}$} \\
\hline & $(7.2)$ & 2,0 & Bom & \\
\hline & (7.3) & 2,0 & Bom & \\
\hline & (7.4) & 0,9 & Fraco & \\
\hline \multirow{5}{*}{ (8) Monitoramento } & $(8.1)$ & 2,4 & Bom & \multirow{5}{*}{$\begin{array}{c}2,1 \\
\text { Bom }\end{array}$} \\
\hline & $(8.2)$ & 2,0 & Bom & \\
\hline & $(8.3)$ & 2,1 & Bom & \\
\hline & (8.4) & 1,7 & Satisfatorio & \\
\hline & (8.5) & 2,2 & Bom & \\
\hline $\begin{array}{l}\text { (9) Dificuldades técnicas e } \\
\text { ausência de informações }\end{array}$ & (9.1) & 0,0 & Muito fraco & $\begin{array}{c}0,0 \\
\text { Muito fraco }\end{array}$ \\
\hline
\end{tabular}




\begin{tabular}{|c|c|c|c|c|}
\hline \multirow{4}{*}{ (10) Participação social } & (10.1) & 2,0 & Bom & \multirow{4}{*}{$\begin{array}{c}1,1 \\
\text { Regular }\end{array}$} \\
\hline & (10.2) & 1,5 & Satisfatorio & \\
\hline & $(10.3)$ & 0,5 & Fraco & \\
\hline & (10.4) & 0,5 & Fraco & \\
\hline \multirow{5}{*}{$\begin{array}{l}\text { (11) Apresentação dos } \\
\text { resultados }\end{array}$} & (11.1) & 2,5 & Muito Bom & \multirow{5}{*}{$\begin{array}{l}2,4 \\
\text { Bom }\end{array}$} \\
\hline & $(11.2)$ & 2,2 & Bom & \\
\hline & $(11.3)$ & 1,9 & Satisfatório & \\
\hline & $(11.4)$ & 3,0 & Muito bom & \\
\hline & (11.5) & 2,3 & Bom & \\
\hline \multirow{4}{*}{ (12) RIMA } & $(12.1)$ & 2,5 & Muito bom & \multirow{4}{*}{$\begin{array}{l}2,4 \\
\text { Bom }\end{array}$} \\
\hline & $(12.2)$ & 1,9 & Satisfatorio & \\
\hline & $(12.3)$ & 2,6 & Muito bom & \\
\hline & (12.4) & 2,5 & Muito bom & \\
\hline & & & & $\begin{array}{c}1,9 \text { (média geral) - } \\
\text { Satisfatório }\end{array}$ \\
\hline
\end{tabular}

Fonte: Pinho et al. (2007).

Considerando os critérios de análise de Lee et al. (1992), a avaliação do estudo apontou que 93\% dos critérios avaliados encontram-se satisfatórios (notas ' $A$ ', ' $B$ ' e ' $C$ ' e $7 \%$ insatisfatórios (notas ' $D$ ' e ' $E$ '). Com base nos critérios de Pinho et al. (2007), a avaliação do estudo resultou que $84 \%$ dos critérios analisados encontram-se satisfatórios ('muito bom', 'bom' e 'satisfatório') e 16\%, insatisfatórios ('muito fraco' e 'regular'). Comparando estas ferramentas de análise, é possível evidenciar que ambas corroboram, apontando para resultados similares demonstrando que o estudo de impacto ambiental avaliado é satisfatório.

Contudo, o estudo ambiental ainda não é isento de críticas, pois vários critérios não foram atendidos adequadamente. Raimundo et al. (2012) avaliando um estudo referente a um empreendimento de aterro sanitário relataram que tal estudo foi insuficiente, pois aspectos importantes não foram adequadamente discutidos, como impactos sobre a biota e interferências em áreas protegidas.

Veronez et al. (2017), analisando a qualidade dos estudos de impacto ambiental no estado do Espírito Santo no período de 2007 a 2013, por meio do procedimento Lee and Colley Review Package relataram a existência de muitos critérios insatisfatórios, destacando-se os referentes à Área 2 (identificação e avaliação de impactos-chave), aspecto relatado também neste estudo. Montaño et al. (2014), realizando uma revisão da qualidade de estudos de impacto ambiental de pequenas centrais hidrelétricas, apontam para inadequações nos critérios relativos à Área 4, comunicação de resultados incluindo aspectos relacionados a participação da sociedade. Resultado este, que corrobora com os resultados descritos neste estudo.

Em síntese, embora as ferramentas utilizadas na análise de revisão da qualidade do estudo avaliado tenham apontado como satisfatório, inúmeras deficiências foram caracterizadas. Muitos impactos negativos (Área 2) não foram mensurados e analisados de maneira exaustiva, como: interferências com áreas de preservação, perdas de ecossistemas, comprometimento da qualidade das águas, impactos na flora e fauna, interferências em patrimônios culturais e históricos e impactos sociais, incluindo populações locais e indígenas.

Constata-se que vários impactos foram minimizados e subestimados, distorcendo os resultados do estudo, principalmente no que se refere à divulgação e publicidade dos documentos para a sociedade. 
Destaca-se que as ferramentas de revisão da qualidade dos estudos ambientais utilizadas neste trabalho são úteis e auxiliam no aperfeiçoamento dos procedimentos de análise dos estudos ambientais, mas ainda assim, apresentam lacunas e limitações, determinadas pelo caráter de subjetividade quanto ao preenchimento dos critérios, que podem se alterar de acordo com a percepção, conhecimento, visão e experiência de cada um, por isso tal preenchimento e análise devem ser feito sempre por mais de um avaliador.

O estudo de impacto ambiental avaliado neste trabalho foi também analisado pelo órgão ambiental licenciador, sendo constatados riscos ambientais em relação a potenciais vazamentos de óleo e gás e descarga de água de lastro contaminada. Outras instituições também emitiram pareceres contestando potenciais emissões de poluentes, associados à formação de chuva ácida e os efeitos ao meio ambiente e a saúde pública.

Ressalta-se que com as ferramentas utilizadas neste estudo para avaliar a qualidade deste empreendimento permitiu detectar deficiências quanto à análise por parte do estudo dos impactos ambientais previstos pelo empreendimento, o que é um ponto positivo. Óbvio que as ferramentas usadas neste trabalho não permitem uma elaboração mais aprofundada da relevância de tais impactos negativos.

Nesse sentido, o órgão ambiental licenciador não aprovou o empreendimento relatando os seguintes argumentos: elevada carga de poluição atmosférica prevista para a região, extensão da supressão de vegetação nativa prevista, impactos negativos na qualidade ambiental preservada dos meios terrestres e marinhos e contraste entre o empreendimento previsto e a vocação da área. Salienta-se que o estudo deixou de abordar aspectos relevantes em relação à viabilidade do projeto, analisando de modo simplista alguns impactos negativos significativos, desconsiderando a complexidade ambiental e social da região.

\section{CONCLUSÕES}

Com o uso das ferramentas avaliativas deste estudo, foi possível mensurar a qualidade do estudo de impacto ambiental analisado. Embora tais aplicações tenham direcionado para uma avaliação satisfatória do estudo, permitiu detectar a existência de vários critérios não atendidos pelo projeto. Tal constatação foi importante, pois corrobora com inúmeros relatos na literatura de deficiências encontradas em estudos de impacto ambiental.

O empreendimento avaliado apresentou carências importantes, como: delimitações das áreas de influência do projeto sem alicerce nas características e fragilidades dos ambientais locais, como praias, costões rochosos, restingas e manguezais e realidades sociais regionais, como unidades de conservação e reservas indígenas, superficialidade no tratamento de impactos socioambientais negativos significativos, tendência à minimização ou subestimação dos impactos negativos e distorção de resultados na comunicação e publicidade do estudo em geral.

As ferramentas utilizadas para análise da qualidade do estudo, embora importantes, apresentam limitações incluindo certo grau de subjetividade na avaliação de seus critérios e aspectos específicos regionais e locais, do ponto de vista da paisagem e sociais. Contudo, ressalta-se que o uso dos critérios 
fomentados nas ferramentas de revisão da qualidade do estudo de impacto ambiental é viável e pode contribuir para o aperfeiçoamento da avaliação de impacto ambiental.

Sugerem-se alguns itens que podem ajudar na melhoria da qualidade dos estudos de impacto ambiental, como: maior integração e interdisciplinaridade entre as equipes que executam os estudos e os órgãos ambientais licenciadores, maior caracterização das realidades paisagísticas e sociais regionais e locais de uma determinada área em função da tipologia do projeto/empreendimento eventualmente proposto para tal área, maior cooperação e intercâmbio de ferramentas e informações de análise em estudos de impacto ambiental por parte dos órgãos ambientais licenciadores, empreendedores, consultorias ambientais, organizações civis, conselhos de classe, institutos de pesquisas e universidades, maior rigor na exigência de qualidade dos estudos de impacto ambiental e estímulo e ampliação da participação popular em diferentes momentos de análise do estudo de impacto ambiental.

\section{REFERÊNCIAS}

ALMEIDA, A. N.; SERTÃO, A. C.; SOARES, P. R. C.; ANGELO, H.. Deficiências no Diagnóstico Ambiental dos Estudos de Impacto Ambiental (EIA). Revista de Gestão Ambiental e Sustentabilidade, v.4, n.1, p.33-48, 2015. DOI: http://doi.org/10.5585/geas.v4i2.168

BARBIERI, J. C.. Gestão Ambiental Empresarial. São Paulo: Saraiva, 2011.

BARKER, A.; WOOD, C.. An evaluation of EIA system performance in eight EU countries. Environmental Impact Assessment Review, v.19, p.387-404, 1999. DOI: https://doi.org/10.1016/S0195-9255(99)00015-3

FONSECA, A.; RESENDE, L.. Boas práticas de transparência, informatização e comunicação social no licenciamento ambiental brasileiro: uma análise comparada dos websites dos órgãos licenciadores estaduais. Engenharia Sanitária Ambiental, v.21, n.2, p.295-306, 2016. DOI: http://doi.org/10.1590/S1413-41522016146591

GLASSON, J.; THERIVEL, R.; CHADWICK, A.. Introduction to environmental impact assessment. London: Routledge, 2005.

GRAY, I.; EDWARD-JONES, G.. A review of environmental statements in the British forest sector. Impact Assessment and Project Appraisal, v.21, p.303-312, 2003. DOI: https://doi.org/10.3152/147154603781766211

HICKIE, D.; WADE, M.. Development of guidelines for improving the effectiveness of environmental assessment. Environmental Impact Assessment Review, v.18, p.267-287 1998. DOI: https://doi.org/10.1016/S0195-9255(98)00005-5

LEE, N.; COLLEY, R.. Reviewing the quality of environmental statements occasional. Manchester: University of Manchester, 1992.

LEE, N.; COLLEY, R.; BONDE, J.; SIMPSON, J.. Reviewing the Quality of Environmental Statements and Environmental Appraisals. Manchester: University of Manchester, 1999.
MONTAÑO, M.; CARVALHO, A. F.; GOMES, C. S.; POLAZ, C. N. M.; JORDÃO, C. O.; SOUZA, M. P.. Revisão da Qualidade de Estudos de Impacto Ambiental de Pequenas Centrais Hidrelétricas. HOLOS Environment, v.14 n.1, p.1-14, 2014. DOI: http://doi.org/10.14295/holos.v14i1.6787

MOUNIR, Z. M.. Evaluation of the quality of environmental impact assessment reports using Lee and Colley package in Niger Republic. Modern Applied Science, v.9, p.89-95, 2015. DOI: http://doi.org/10.5539/mas.v9n1p89

MPF. Ministério Público Federal. Deficiências em Estudos de Impacto Ambiental: Síntese de uma Experiência. Brasília: MPF, 2004.

PEREIRA, J. A. A.; BORGES, L. A. C.; BARBOSA, A. C. M. C.; BOREM, R. A. T.. Fundamentos da Avaliação de Impactos Ambientais com estudo de caso. Lavras: UFLA, 2014.

PINHO, P.; MAIA, R.; MONTERROSO, A.. The quality of Portuguese Environmental Impact Studies: the case of small hydropower projects. Environmental Impact Assessment Review, v.27, p.189-205, 2007. DOI: https://doi.org/10.1016/j.eiar.2006.10.005

RAIMUNDO, M. R.; MALFARÁ, D. T.; MENDES, N. C.; MORAES, M, C. P.; SOUZA, M. P.. Aplicação de Métodos para Revisão da Qualidade de Estudos de Impacto Ambiental. Revista de Gestão Ambiental e Sustentabilidade, v.1, n.2, p.1-28, 2012. DOI: http://doi.org/10.5585/geas.v1i2.20

ROSA, A. H.; FERNANDES-FRACETO, L.; MOSCHINI-CARLOS, V.. Meio Ambiente e Sustentabilidade. Porto Alegre: Bookman, 2012.

SÁNCHEZ, L. E.. Avaliação de Impacto Ambiental: conceitos e métodos. São Paulo: Oficina de Textos, 2013.

VERONEZ, F.; MONTAÑO, M.. Análise da qualidade dos estudos de impacto ambiental no Estado do Espírito Santo (2007-2013). Desenvolvimento e Meio Ambiente, v.43, p.621, 2017. DOI: http://doi.org/10.5380/dma.v43i0.54180

A CBPC - Companhia Brasileira de Produção Científica (CNPJ: 11.221.422/0001-03) detém os direitos materiais desta publicação. Os direitos referem-se à publicação do trabalho em qualquer parte do mundo, incluindo os direitos às renovações, expansões e disseminações da contribuição, bem como outros direitos subsidiários. Todos os trabalhos publicados eletronicamente poderão posteriormente ser publicados em coletâneas impressas sob coordenação da Sustenere Publishing, da Companhia Brasileira de Produção Científica e seus parceiros autorizados. Os (as) autores (as) preservam os direitos autorais, mas não têm permissão para a publicação da contribuição em outro meio, impresso ou digital, em português ou em tradução. 